\title{
New evidence on the puzzles: Results from agnostic identification on monetary policy and exchange rates ${ }^{\text {is }}$
}

\author{
Almuth Scholl ${ }^{\mathrm{a}, *}$, Harald Uhlig ${ }^{\mathrm{b}}$ \\ a Johann Wolfgang Goethe Universität Frankfurt am Main, Fachbereich Wirtschaftswissenschaften, Mertonstr. 17, PF 96, 60054 Frankfurt am Main, Germany \\ b The University of Chicago, Department of Economics, 1126 East 59th Street, Chicago, IL 60637, USA
}

Keywords:

Vector autoregressions

Agnostic identification

Forward discount puzzle

Delayed overshooting

Exchange rates

Monetary policy

JEL classification:

C32

E58

F31

F42

\begin{abstract}
A B S T R A C T
Past empirical research on monetary policy in open economies has found evidence of the 'delayed overshooting puzzle' and the 'forward discount puzzle'. We revisit the effects of monetary policy on exchange rates by applying Uhlig's [Uhlig, H., 2005a. What are the effects of monetary policy on output? Results from an agnostic identification procedure. Journal of Monetary Economics 52(2), 381-419.] identification procedure that involves sign restrictions on the impulse responses of selected variables. In a first step, we leave the response of the exchange rate agnostically open and find sizeable evidence for both puzzles. In a second step, we additionally rule out the delayed overshooting by construction. Our results indicate that the forward discount puzzle is robust even without delayed overshooting.
\end{abstract}

(c) 2008 Elsevier B.V. All rights reserved.

\section{Introduction}

What are the effects of monetary policy on exchange rates? For the answer, there is a sharp conflict between baseline theory and baseline evidence. Dornbusch's (1976) well known overshooting hypothesis predicts that an increase in domestic interest rates relative to foreign interest rates leads to an impact appreciation followed by a persistent depreciation of the domestic currency. Following the lead of Sims (1972, 1980), however, empirical studies have found different results employing vector autoregressions (VARs) in open economy settings.

To study the effects of monetary policy on exchange rates, e. g. Eichenbaum and Evans (1995) and Grilli and Roubini (1995, 1996) use recursive identification strategies and find a persistent appreciation of the domestic currency for periods up to 3 years. This finding is known as the 'delayed overshooting puzzle', see Fig. 1, and is also reported in Leeper et al. (1996), Clarida and Gali (1994), and Kim (2001, 2005). It is often called the 'forward discount puzzle', see Fig. 2, since a violation of the uncovered interest parity (UIP) condition is implied. More generally, there may be a forward discount puzzle even without delayed overshooting.

\footnotetext{
is This research was supported by the Deutsche Forschungsgemeinschaft through the SFB 649 “Economic Risk" and by the RTN network MAPMU. We are grateful to suggestions of two anonymous referees and comments received at Princeton, MIT, NYU, and at the "Macroeconomics and Reality: 25 years later" conference in Barcelona, April 2005.

* Corresponding author.

E-mail addresses: ascholl@wiwi.uni-frankfurt.de (A. Scholl), huhlig@uchicago.edu (H. Uhlig).
} 


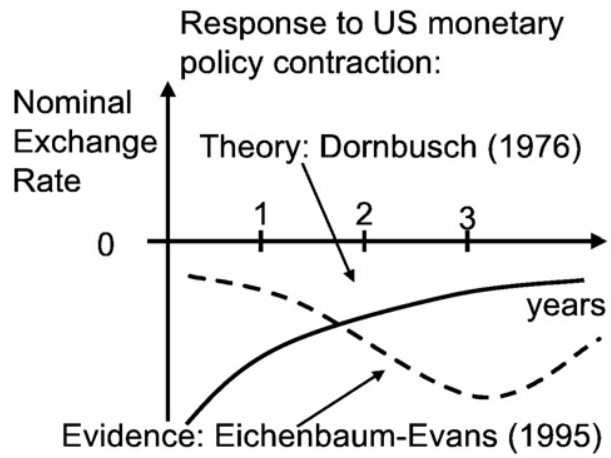

Fig. 1. A stylized representation of the delayed overshooting puzzle.

Recently, this conventional view has come under attack, see e.g. Cushman and Zha (1997), Kim and Roubini (2000) and Faust and Rogers (2003). ${ }^{1}$ Faust and Rogers (2003) argue, that one needs to "relax dubious identifying assumptions" stemming from e.g. recursive identifications and impose at most rather mild sign restrictions or shape restrictions a priori. In response to monetary policy shocks they find no robust results regarding the timing of the peak response of the exchange rate, but robust evidence in favor of large deviations from UIP due to monetary policy shocks. Like Faust and Rogers (2003), Farrant and Peersman (2006) use sign restrictions to investigate the sources of exchange rate movements.

This paper re-examines these issues by using Uhlig's (2005a) identification strategy of imposing sign restrictions on selected impulse response functions for a certain period following the shock. We focus on two questions. First, is there robust evidence of a delayed overshooting of the exchange rate in response to monetary policy shocks? Second, does the forward discount puzzle still survive or is it just a 'twin appearance' of delayed overshooting? ${ }^{2}$ This question is of interest, since the delayed overshooting observation may be interpreted as a sign of failing to appropriately identify monetary policy shocks, see Cushman and Zha (1997).

To analyze the first question, our identification procedure assumes that domestic contractionary monetary policy shocks do not lead to decreases in the domestic short-term interest rate, increases in the domestic price level and increases in the ratio of nonborrowed to total reserves during the first year following the shock. Hence, by construction our identification procedure avoids the price puzzle that is often implied by recursive identification strategies. Note that at this stage we do not impose any restrictions on the exchange rate to leave the central question agnostically open. We argue that these sign restrictions are plausible because they most directly reflect what economists have in mind when thinking about monetary policy shocks. For the second question, we rule out delayed overshooting by construction. More precisely, we additionally impose that the difference between the domestic interest rate and the foreign interest rate is positive, that the exchange rate moves strongest on impact and that its impulse response is monotonously declining for a few periods afterwards. Our restrictions only concern the shape and not the size of the exchange rate response.

Similar to Faust and Rogers (2003), we apply our identification method to the VAR specification used by Eichenbaum and Evans (1995). Following the arguments of Sims and Uhlig (1991) we use a thoroughly Bayesian procedure. We provide posterior distributions regarding the parameters of interests, like the time and the size of the peak response.

While the focus in Faust and Rogers (2003) is on a robustness analysis using minimal assumptions, we view the sign restrictions as a means to identifying monetary policy shocks, imposing a uniform prior on all suitably normalized impulse vectors satisfying the sign restrictions, see Uhlig (2005a). Faust and Rogers (2003) impose most of their restrictions on-impact only, occasionally complemented by shape restrictions on the exchange rate response, see the bottom half of page 1419 in their paper. As a result, they allow for the possibility that expansionary monetary policy shocks and a surprise drop in interest rates trigger falling rather than rising prices during the first year following the shock, followed eventually by increased interest rates and rising prices, see their Fig. 2. By contrast, we impose sign restrictions on the impulse responses for prices as well as key monetary policy variables during a full year or, alternatively, half a year after the shock. We argue that the larger set of sign restrictions is reasonable, as it avoids by construction the price puzzle and delayed liquidity puzzle visible in their figure.

With our larger set of sign restrictions, we narrow down the range of possible monetary policy shocks considerably, as has already been argued in Uhlig's (1998) discussion of Faust (1998). Thus, and in contrast to Faust and Rogers (2003), who argue that delayed overshooting is a fragile finding, we restore the puzzle originally stated by Eichenbaum and Evans (1995). We find sizeable and robust evidence in favor of a delayed overshooting of the US-German, the US-UK and the US-Japanese bilateral exchange rates as well as confronting the US with an aggregate of the other G7 countries. In line with Eichenbaum and Evans (1995) and Faust and Rogers (2003) we find a robust forward discount puzzle implying a large risk premium conditional on monetary policy shocks.

We exploit the Bayesian perspective to ask questions concerning the risk a Bayesian investor faces when betting on violations of UIP. We calculate an implied Sharpe ratio conditional on the monetary policy shock and show it to be considerably higher than the Sharpe ratios conventionally observed on US equity markets. Even if we rule out the delayed overshooting puzzle by construction, we do find strong posterior evidence for sizeable risk premia across all country pairs. Thus, the forward discount puzzle seems to be robust even without delayed overshooting. Notably, our findings are in contrast to Cushman and Zha (1997) and Kim and Roubini (2000) who

\footnotetext{
${ }^{1}$ Other papers that do not find evidence of the delayed overshooting puzzle are e.g. Kalyvitis and Michaelides (2001) and Bjørnland (2006).

${ }^{2}$ We are grateful to an anonymous referee for this suggestion.
} 


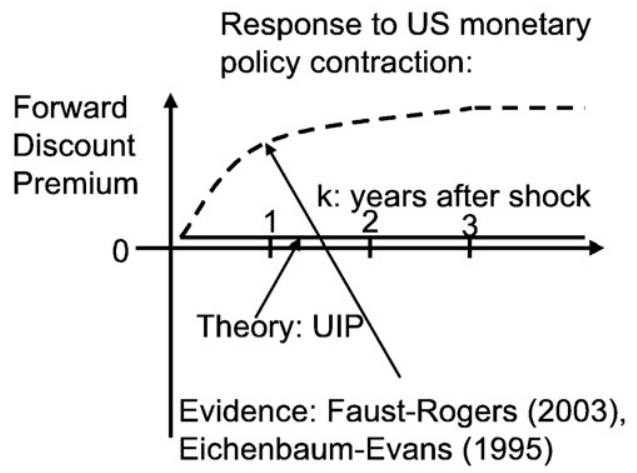

Fig. 2. A stylized representation of the forward discount puzzle.

identify monetary policy shocks by explicitly modeling policy reaction functions and the structure of the economy. They find no evidence of delayed overshooting and, in addition, no statistically significant evidence of large deviations from UIP.

The structure of the paper is as follows. In Section 2 we present the theoretical framework. Section 3 describes our empirical approach. Section 4 reports the results and, finally, Section 5 concludes.

\section{Overshooting, the forward discount premium and the Sharpe ratio}

The Dornbusch (1976) overshooting of the exchange rate follows from uncovered interest parity (UIP), long-run purchasing power parity (PPP) and a liquidity effect in response to monetary policy shocks, and is a feature that many theoretical models have in common. Recently, stochastic dynamic general equilibrium models with monetary policy policy shocks have been employed to explain the volatility and the persistence of the exchange rate, see e. g. Alvarez et al. (2002, 2006), Chari, Kehoe and McGrattan (2002), Kollmann (2001) and Bergin (2006). In line with Dornbusch's prediction, these models imply that an increase in the interest rate differential leads to an impact appreciation of the exchange rate followed by depreciation, see the impulse responses in Bergin (2006). The Dornbusch overshooting model and UIP are explained well in e.g. Obstfeld and Rogoff (1996), Sections 8.2.7 and 9.2. Here, we just provide a brief summary in order to fix notation and to provide a framework for the empirical analysis to follow.

Importantly and as has also been emphasized by Faust and Rogers (2003), we do not consider UIP and the overshooting hypothesis in general, but only conditional on a monetary policy shock. A key question is: how much of a change or deviation from UIP should one expect following a monetary policy shock?

Thus, let $s_{k}$ be the impulse response of the log of the nominal exchange rate, understood throughout the paper to be Dollars ('home') per unit of non-US ('foreign') currency. Let $i_{k}$ and $i_{k}^{*}$ be the impulse response for the US and the foreign short-term rates, respectively. This allows the calculation of the compounded return from investing (or borrowing) at this rate from 0 to $k$,

$$
i_{0 \rightarrow k}=\sum_{j=0}^{k-1} i_{j}, \quad i_{0 \rightarrow k}^{*}=\sum_{j=0}^{k-1} i_{j}^{*} .
$$

Define the forward discount premium

$$
\rho^{k}=s_{0}-s_{k}+i_{0 \rightarrow k}-i_{0 \rightarrow k}^{*}
$$

which is the gain due to the monetary policy shock (compared to the baseline scenario without that shock) from borrowing foreign currency for $k$ periods following the monetary policy shock at the foreign short rate, exchanging it for Dollars, investing it at the US rate, and exchanging it back again in period $k$. Note that one can write

$$
\rho^{k}=\sum_{j=1}^{k} \xi_{j}
$$

where

$$
\xi_{j}=s_{j-1}-s_{j}+i_{j-1}-i_{j-1}^{*}
$$

is the same gain when executing this hedging strategy only from periods $j-1$ to $j$ following the shock. In particular, $\rho_{j}$ stays flat for $j \geq j^{*}$, if $\xi_{j}=0$ for $j \geq j^{*}$.

Conditional uncovered interest parity (UIP) in the context of our analysis says that one should not be able to make (or loose) money via these hedging strategies, i.e. $\rho_{k} \equiv 0$ for all $k$ or $\xi_{j} \equiv 0$ for all $j$. This appears to be in conflict with the evidence found in the literature, see Fig. 2. In the empirical literature it is common to assume rational expectations and to employ regressions of exchange rate movements on interest rate differentials to study the (unconditional) forward discount premium, see Hansen and Hodrick (1980), Fama (1984), Froot and Thaler (1990) and Lewis (1995) who provides an excellent survey. Our study of forward premia and the associated empirical Sharpe ratios conditional on monetary policy shocks using VARs complements this literature. 
Table 1

Identification of monetary policy shocks

\begin{tabular}{ll}
\hline Variables & $y, y^{*}, p, n b r x, i, i^{*}, s$ \\
Identification I & $p\left(k_{1}\right) \leq 0, n b r x\left(k_{1}\right) \leq 0, i\left(k_{1}\right) \geq 0$ \\
Identification II & $p\left(k_{2}\right) \leq 0, n b r x\left(k_{2}\right) \leq 0, i\left(k_{2}\right) \geq 0, i\left(k_{2}\right)-i^{*}\left(k_{2}\right)>0$ \\
& $s(0)<0,|s(j)|<|s(j-1)|,|s(\tilde{j})|<|s(0)|$
\end{tabular}

Notes: Identification I is based on the horizon $k_{1}=0, \ldots, K_{1}, K_{1}=11$, i.e. 1 year. Identification II is based on the horizon $k_{2}=0, \ldots, K_{2} K_{2}=5, j=0, \ldots, J, J=2$ and $\bar{j}=J+1, \ldots, \tilde{J}$, $\tilde{J}=23 . y$ and $y^{*}$ denote domestic and foreign industrial production, $p$ is the domestic price level, $i$ and $i{ }^{*}$ are the domestic and foreign short-term rates, $n b r x$ denotes the ratio of nonborrowed reserves to total reserves and $s$ is the nominal exchange rate.

Rewrite the definition of $\xi_{j}$ as

$$
s_{j}-s_{j-1}=i_{j-1}-i_{j-1}^{*}-\xi_{j}
$$

With the additional assumption $i_{j-1}-i_{j-1}^{*}>0$, the exchange rate must depreciate, $s_{j}>s_{j-1}$, if $\xi_{j} \equiv 0$. According to Dornbusch's (1976) overshooting model, this is what the exchange rate should do, following a surprise domestic monetary tightening and an initial appreciation to assure long-run purchasing power parity. However, the empirical literature has found delayed overshooting in response to US monetary policy contractions, see Fig. 1. Therefore, the forward discount puzzle is often viewed as an implication of this delayed overshooting puzzle, but note that the latter observation requires additional assumptions like the ones stated above in order to be puzzling. In reaction to the empirical findings, there have been some recent attempts to develop theoretical explanations. Gourinchas and Tornell $(2002,2004)$ explain the delayed overshooting as the interaction of learning about the current state and the intrinsic dynamic response of interest rates to monetary shocks. Other recent papers like e.g. Moore and Roche (2002), Backus et al. (2001), Verdelhan (2006) and Bacchetta and van Wincoop (2005) consider habit-persistence or rational inattention.

The equation above also suggests the following perspective. While exchange rate movements certainly depend on the policy rules of both countries, the resulting interest differential $i_{0}-i_{0}^{*}>0$ is essential. Regarding our empirical analysis, we argue that it is sufficient to focus on the interest rate differential since it reflects cross-country policy differences through the liquidity effect of monetary policy.

Even if the overshooting puzzle can be resolved, the forward discount puzzle may remain. To investigate it further, note that the hedging strategies described above are conditional on a single monetary policy shock only. To literally execute such a strategy in practice, where one wishes to only exploit possible gains from a single monetary policy shock, one would need to 'insure' away all other influences such as other contemporaneous and all future shocks until maturity $k$. While many papers in the literatureincluding Faust and Rogers (2003)-have documented (explicitly or implicitly) significant violations of conditional UIP, this may not suffice for an investor contemplating exploiting this deviation at some date $t$.

Consider thus the perspective of a Bayesian investor, who trades contingent on a monetary policy shock, and uses the methods of this paper to assess the posterior uncertainty regarding the resulting forward discount premium. Note that one may think of this premium as the excess return for investing in the domestic interest rate over investing in the foreign rate, starting and ending with a position in foreign currency. Let $\mu_{\rho k}$ and $\sigma_{\rho k}$ be the Bayesian posterior mean and standard deviation for $\rho_{k}$. Define the Sharpe ratio $S R_{\rho k}=\mu_{\rho k} / \sigma_{\rho k}$ to measure the estimation risk of the hedging strategy. Put differently, while the structural VAR at its true coefficients and its true identification of the monetary policy shock would predict a certain and riskless response of the forward premium, that truth is not known to the Bayesian investor. She therefore might as well treat that response as stochastic, reflecting estimation uncertainty.

To provide a comparison and benchmark, consider the Sharpe ratio from investing in equity and its uncertain returns versus the riskless rate. For an investment horizon of 1 year, a Sharpe ratio of approximately 0.5 is commonly stated in the literature. This converts into a benchmark Sharpe ratio of $0.5 \sqrt{k / 12}$ for an investment horizon of $k$ months, if one assumes excess returns to be i.i.d. We shall compare the Sharpe ratios $\mathrm{SR}_{\rho k}$ to this value.

\section{Our approach}

\subsection{Methodology}

In the following we briefly describe the methodology introduced by Uhlig (2005a). This methodology builds on the classic paper by Leamer (1981) and its macroeconomic implementation by Blanchard (1989). It is related to work by Canova and Pina (1999), Canova and de Nicolo (2002), Dwyer (1997), Faust (1998) and Gambetti (1999). Recently, Rubio-Ramírez et al. (2005) provide an efficient algorithm to implement sign restrictions in Markov-switching SVARs.

Consider a vector autoregression

$$
Y_{t}=B_{(1)} Y_{t-1}+B_{(2)} Y_{t-2}+\ldots B_{(n)} Y_{t-n}+u_{t}, E\left[u_{t} u_{t}^{\prime}\right]=\sum,
$$

$t=1 \ldots T$, for some $\ell$-dimensional vector of variables $Y_{t}$, coefficient matrices $B_{(i)}$ of size $\ell \times \ell$ and a variance-covariance matrix for the one-step ahead prediction error $\sum$. Write the one-step ahead prediction error $u_{t}$ as a linear combination of orthogonalized 'structural' shocks,

$$
u_{t}=A_{v_{t}}, E\left[v_{t} v_{t}^{\prime}\right]=I
$$


Traditional identification strategies impose a recursive ordering or structural restrictions on $A$ or $A^{-1}$. Here, we seek to identify one shock in particular, i.e. the monetary policy shock. To that end, the following definition is helpful.

Definition 1. The vector $a \in \mathbb{R}^{\ell}$ is called an impulse vector, if there is some matrix $A$, so that $A A^{\prime}=\sum$ and so that $a$ is a column vector of $A$.

Simple matrix algebra shows that any impulse vector $a$ can be characterized by $a=\tilde{A} \alpha$, where $\tilde{A} \tilde{A}^{\prime}=\sum$ is some decomposition, e.g. the Cholesky decomposition, of $\sum$ and $\alpha$ is an $\ell$-dimensional vector of unit length. Let $r_{j}(k) \in \mathbb{R}^{\ell}$ be the vector response at horizon $k$ to the $j$ th shock in a Cholesky-decomposition of $\sum$. Then the vector impulse response $r_{a}(k)$ for a is given by

$$
r_{a}(k)=\sum_{j=1}^{\ell} \alpha_{j} r_{j}(k) .
$$

We now follow Uhlig (2005a) and identify the monetary policy shock per sign restrictions. More specifically, we impose that entries of the vector impulse response $r_{a}(k)$ at various horizons $k$ satisfy a list of inequality restrictions, listed in Table 1.

We use a Bayesian prior for the VAR parameters $(B, \Sigma)$ and an independent uniform prior for $\alpha$. The uniform prior for $\alpha$ assures that the implied prior for $\alpha$ is independent of the specific decomposition $\tilde{A} \tilde{A}^{\prime}=\sum$ and can even be random as long as the choice of the decomposition is independent of $\alpha$. It amounts to treating all canonically normalized impulse vectors as equally likely, provided they satisfy the sign restrictions. For further methodological details see Uhlig (2005a).

The procedure generates posterior distributions for any particular statistic of interest, such as the impulse response of some variable at some horizon or the period of its peak response. Obviously, posterior medians for different statistics may not be generated by the same point in the parameter space. Therefore, the usual caution should be exercised in interpreting, say, a plot of the median impulse response. This has recently been emphasized by Fry and Pagan (2007) as an issue arising with sign restrictions, but it is an issue arising generally for most identification procedures. They also state their scepticism regarding the ability of the sign restriction methodology to appropriately identify shocks. We do not share their point of view, and point to the analysis of a simple supply-demand example in Uhlig (2005b).

\subsection{Identification of monetary policy shocks}

To assure comparability and similar to Faust and Rogers (2003), we use the specification chosen by Eichenbaum and Evans (1995). We study three country pairs: the US and Germany, the US and the UK, and the US and Japan. To additionally take into account cross-sectional information we construct an aggregate of the six G7 countries other than the US. For the three country pairs we employ monthly data from 1975:07 to 2002:07 while for the aggregate we have monthly data from 1977:04 to 2001:12 due to data limitations. For each country pair, seven variables are included: US and foreign industrial production $y$ and $y^{*}$, US and foreign 3-months interest rates $i$ and $i^{*}$, the US ratio of nonborrowed to total reserves $n b r x$, the US consumer price index $p$ and the nominal exchange rate $s$. Variables are in logs, except for the interest rates. A detailed description of the variables, the data sources and the construction of the aggregate can be found in the Appendix A.

The advantage of the Eichenbaum-Evans specification is the inclusion of the ratio of nonborrowed reserves to total reserves as a monetary aggregate which a number of researchers have argued to be closely related to monetary policy choices, see e.g. Christiano and Eichenbaum (1992) and Strongin (1995).

Table 1 provides a detailed description of the VAR specification and the set of sign restrictions used. In order to study the robustness of the delayed overshooting puzzle our first identification set imposes that prices as well as the ratio of nonborrowed to total reserves do not rise in response to a monetary contraction. Thus, 'price puzzles' are avoided by construction. We furthermore match conventional wisdom by imposing that, in response to a domestic monetary policy contraction, domestic interest rates do not fall. Crucially, at this stage, we leave the exchange rate unrestricted to leave the question at hand agnostically open.

As argued by Cushman and Zha (1997), the delayed overshooting may be a sign of failing to appropriately identify the monetary policy shock. The methodology here allows us to impose the absence of delayed overshooting in the presence of a (relative) monetary tightening: this is what we do in the identification strategy II. We impose two additional assumptions. First, the US Dollar initially appreciates in response to a monetary policy shock and then persistently depreciates. Second, the interest rate differential is constrained to be positive. The question now is: does the forward discount puzzle still survive or is it just a 'twin appearance' of delayed overshooting? Put differently, we ask: if there is an increase in the interest rate differential and the exchange rate shows no delayed overshooting, is UIP fulfilled then, or is there still a forward discount premium?

For the horizon of the sign restrictions, our first identification scheme uses $k_{1}=0, \ldots, K_{1}=11$, i.e. 1 year. Choosing shorter restrictions leaves too much room for spurious effects while imposing a longer horizon imposes an implausibly long duration of the liquidity effect. Since our second identification avoids the delayed overshooting puzzle by construction and therefore imposes very tight identifying assumptions, we choose a horizon of half a year, $k_{2}=0, \ldots, K_{2}=5$ for the responses of the interest rates, the price level and the monetary aggregate. Moreover, we restrict the exchange rate to appreciate on impact and to depreciate during the first quarter following the shock. In addition, to ensure the persistency of the depreciation, for 2 years following the shock, the response of the exchange rate is constrained to be smaller in absolute value compared to the impact response. Uhlig (2005a) contains some discussions how results vary with the horizon when applying the methodology in the analysis of monetary policy shocks for US data. To save space we decided to omit results for other choice of the horizon length. We experimented with the set of identifying sign restrictions and provide a discussion in our robustness analysis. 
75:07-90:05

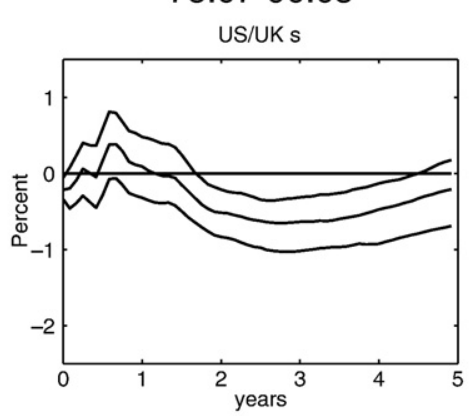

S

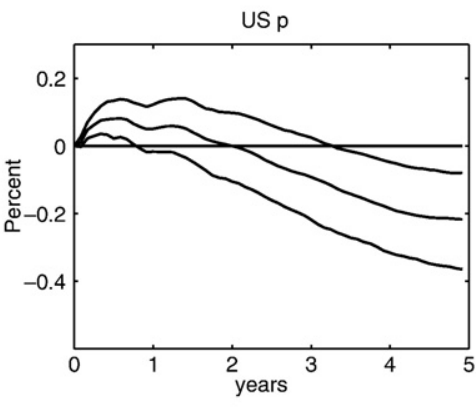

75:07-02:07

US/UK s

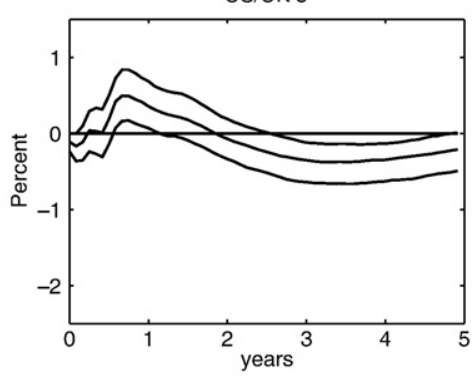

US $p$

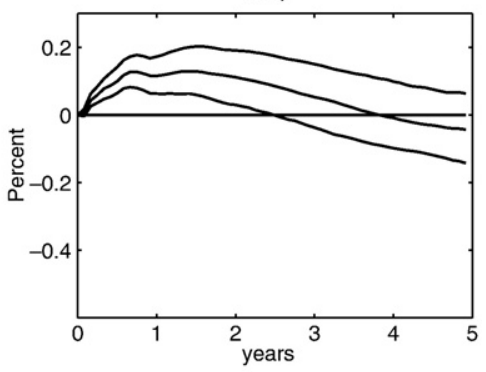

Fig. 3. The US-UK: recursive identification. Notes: The identification scheme proposed by Eichenbaum and Evans (1995) is applied. The median impulse response and the $16 \%$ and $84 \%$ quantiles of the distribution are shown.

A Bayesian VAR with 6 lags in levels of the logs of the series has been fitted to the monthly data except for using interest rates directly. No constant or time trends are included. This may result in a slight misspecification but the results are more robust because of the interdependencies in the specification of the prior between these terms and the roots in the autoregressive coefficients, see Uhlig (1994). In our robustness analysis later on we find that our findings are not sensitive with respect to this modeling choice.

The prior and therefore the posterior belong to the Normal-Wishart family, see Uhlig (1994) for a detailed discussion of the properties. Results are obtained by taking draws from the posterior for the VAR coefficients and draws from the space of possible impulse vectors. Inference statements are based on the joint draws that satisfy the sign restrictions for the impulse responses. We typically show the median and the $16 \%$ and $84 \%$ quantiles of the distribution for the points on the impulse response functions.

\section{Empirical results}

\subsection{The delayed overshooting puzzle}

We start by considering the identification strategy by Eichenbaum and Evans (1995) who impose the recursive ordering [ $y$, $p$, $\left.y^{*}, i^{*}, n b r x, i, s\right]$ and define a monetary contraction by a fall in the ratio of nonborrowed reserves to total reserves. Fig. 3 considers the US-UK as an example and plots the impulse responses of the nominal exchange rates and the price level considering two data sets. The first data set ends in 1990:05 and corresponds to the one in Eichenbaum and Evans (1995). The second data set we use for our analysis is updated and ends in 2002:07. For the original data set we find a persistent appreciation for periods up to 3 years as in Eichenbaum and Evans (1995). Using the updated data set instead, we find a slightly less strong reaction of the exchange rate but the pattern appears qualitatively to be very similar. Since the impulse responses of the USGerman and the US-Japanese bilateral exchange rates follow a similar pattern we omit the figures to save space. The second line of Fig. 3 reveals that there emerges a huge price puzzle that is even more pronounced for the updated data set. We believe that this strong and long positive reaction of the price level casts considerable doubt on this identification strategy and therefore on the results for the exchange rate response.

By contrast, our sign restrictions avoid the price puzzle by construction. For the first idenfication, Fig. 4 plots the impulse responses of the nominal and real exchange rate, $s$ and $q$, the interest rate differential $i-i^{*}$, the forward discount premium $\rho$ and the associated Sharpe Ratio $\mathrm{SR}_{\rho}$. The other variables like e.g. the price level are restricted and therefore are omitted to save space. US industrial production does not show a significant response. In response to monetary policy shocks the interest rate differentials between the domestic and foreign short-term interest rates increase which matches conventional wisdom. 

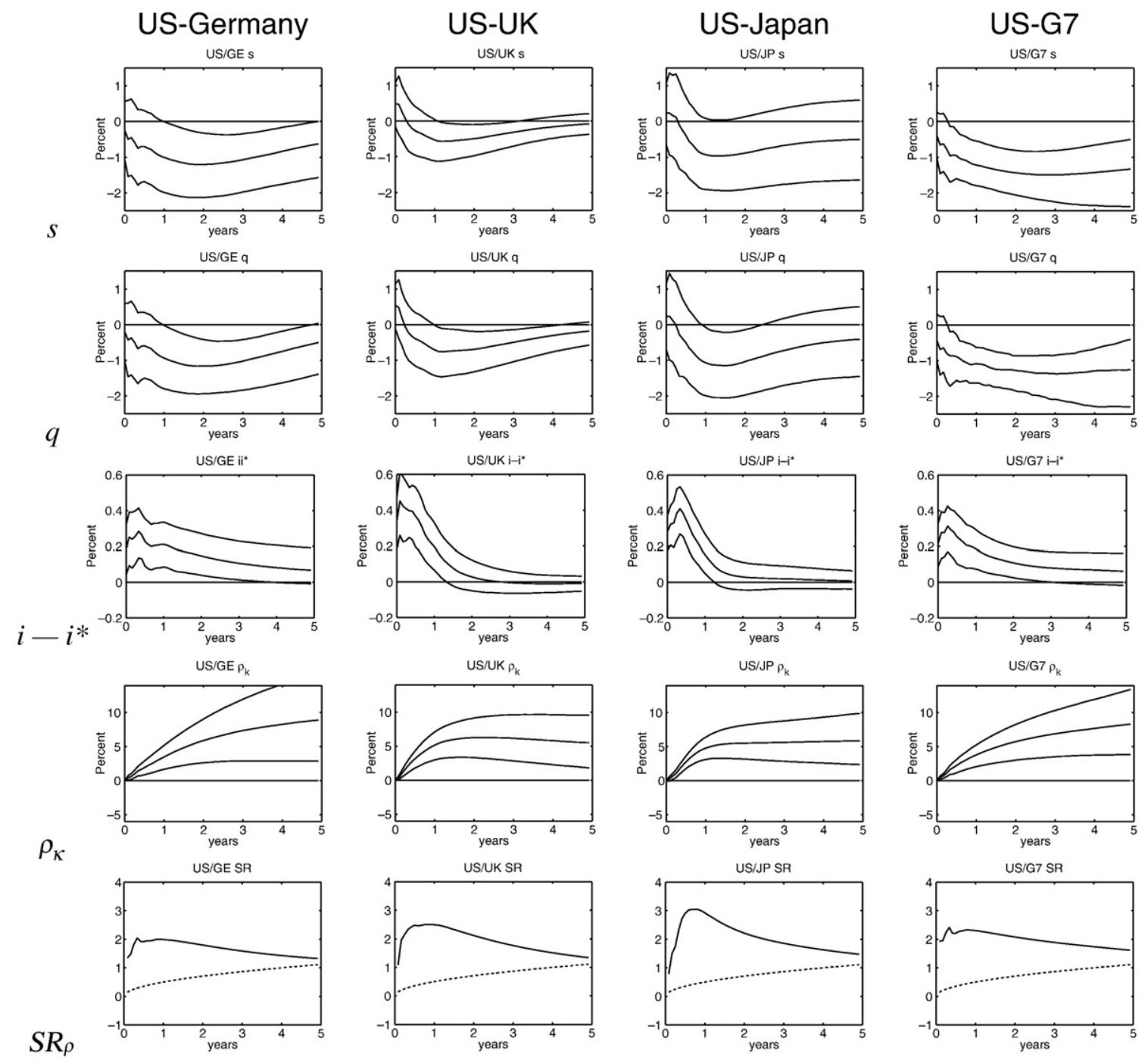

Fig. 4. Evidence on the delayed overshooting puzzle. Notes: Results refer to identification I (see Table 1). The median impulse response and the $16 \%$ and $84 \%$ quantiles of the distribution are shown.

The first line of Fig. 4 shows the impulse responses of the nominal exchange rate and should be compared to Fig. 1. The median impulse response for all three country pairs shows an appreciation of the exchange rate until a peak at 1 to 2 years after the shock followed by depreciation, surrounded by considerable posterior uncertainty in particular for the US-UK and US-Japan case. The evidence for a persistent appreciation is stronger in the US-G7 case shown in the last column. The second line of Fig. 4 shows the impulse response of the real exchange rate. It turns out that the nominal and the real exchange rates respond very similar to monetary policy shocks which is in line with the results in Eichenbaum and Evans (1995). In the following we therefore focus on the nominal exchange rate.

Since the median impulse response may not come from any particular point in the parameter space, and given the sizeable posterior uncertainty, it is difficult inferring posterior information from Fig. 4 about a statistic of particular interest, namely the period of the peak response. To answer this question the first column of Fig. 5 shows the posterior distribution of the timing of the peak appreciation, i.e. the distribution of the month containing the lowest point of an impulse response drawn from the posterior. Table 2 provides summary statistics for that posterior distribution. Evidently, the bulk of the mass shows a peak response somewhere between 5 and 53 months after the shock, or even later for the G7 case. Most importantly, there is little weight assigned to an early or even immediate peak response: in no case did the posterior probability for a peak response during the first quarter exceed the value of $7 \%$.

But one may still remain sceptical. It could be that the posterior distribution of the peak months gives misleading results, if e.g. impulse responses showing strong appreciations peak early and those with mild appreciations peak late. We therefore analyze the size of the peak appreciation in addition to the timing. The second column of Fig. 5 shows the posterior joint distributions of the 


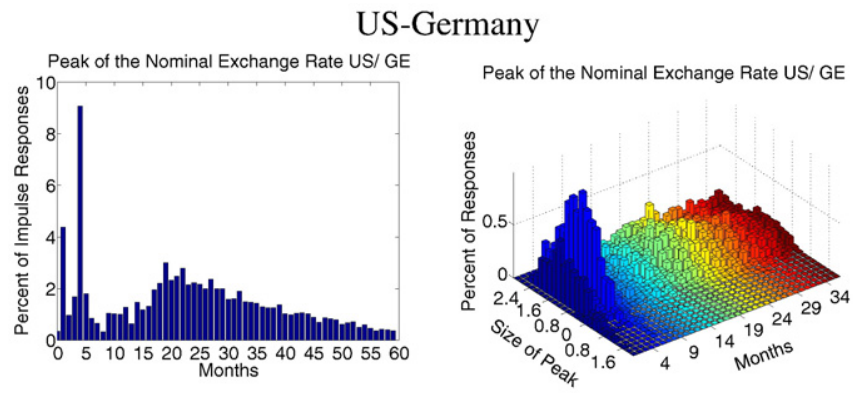

US-UK
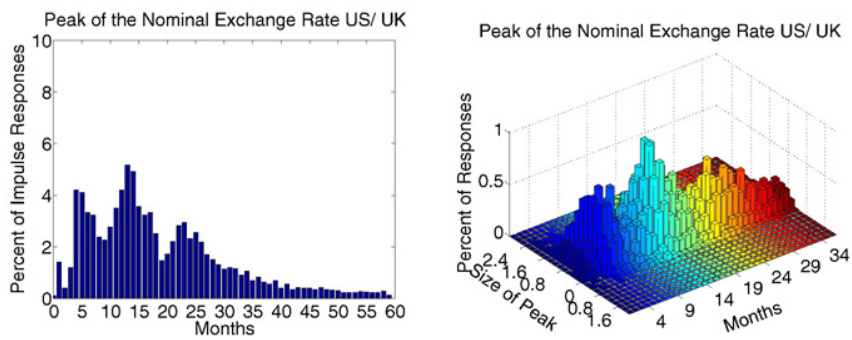

US-Japan

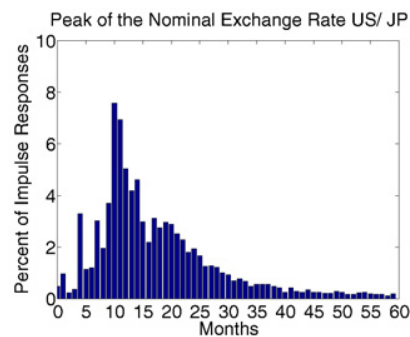

Peak of the Nominal Exchange Rate US/ JP

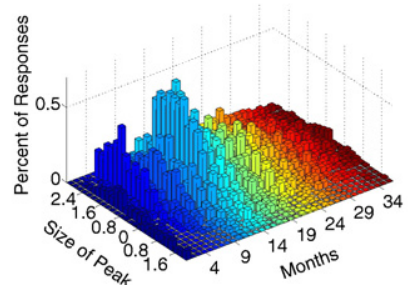

US-G7

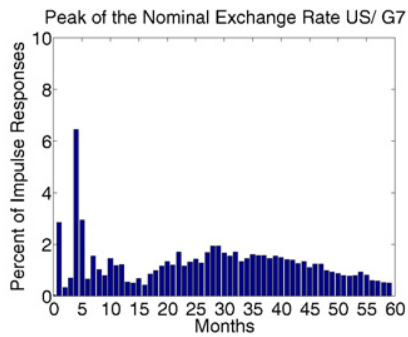

Peak of the Nominal Exchange Rate US/ G7

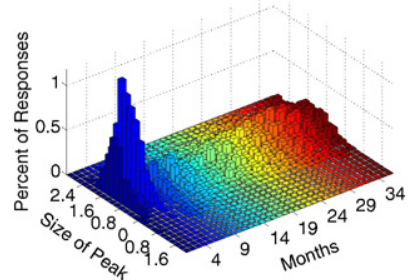

Fig. 5. Properties of the peak of the nominal exchange rate. Notes: Results are conditional on a US monetary policy contraction and refer to identification I (see table 1 ) based on 10,000 draws. The marginal distribution as well as the posterior distribution for the size and timing of the peak appreciation $s(k)$ are shown.

timing of the peak and its altitude. A visual comparison to the one-dimensional histogram in the first column reveals that there is at most modest dependency between the size and the timing of the peak. If anything, early peaks are small peaks, thus strengthening the insights from the first column.

Our results suggest that, in contrast to e.g. Kim and Roubini (2000) and Faust and Rogers (2003), there is robust evidence for a delayed overshooting. The median delay is somewhat shorter than the 3-year horizon found by Eichenbaum and Evans (1995), except for the G7 case.

\subsection{The market price for the forward discount risk}

How large are the forward premia conditional on monetary policy contractions? What risk does a Bayesian investor face when betting on violations of UIP and what is the reward of doing so?

To analyze these questions the last two lines of Fig. 4 focus on the impulse responses of the forward premia for $k$-month holding periods, $\rho^{k}$, as well as the corresponding Sharpe ratios $\mathrm{SR}_{\rho}$. On stock markets annual Sharpe ratios of 0.5 are commonly observed. 
Table 2

Distribution of the peak response

\begin{tabular}{|c|c|c|c|c|c|}
\hline & $\%$ in first quarter & $16 \%$ & Median & $84 \%$ & $>60 \mathrm{mo}$ \\
\hline US-Germany & $6 \%$ & $5 \mathrm{mo}$ & $26 \mathrm{mo}$ & $53 \mathrm{mo}$ & $12 \%$ \\
\hline US-UK & $2 \%$ & $8 \mathrm{mo}$ & $17 \mathrm{mo}$ & $35 \mathrm{mo}$ & $6 \%$ \\
\hline US-Japan & $2 \%$ & $10 \mathrm{mo}$ & $18 \mathrm{mo}$ & $45 \mathrm{mo}$ & $13 \%$ \\
\hline US-G7 & $3 \%$ & 9 mo & $36 \mathrm{mo}$ & $>60 \mathrm{mo}$ & $24 \%$ \\
\hline
\end{tabular}

Notes: Summary statistics for the posterior distribution of the peak response. Listed are the posterior probabilities for a peak response during the first quarter, as well as the months corresponding to the $16 \%$, the $50 \%$ and the $84 \%$ quantile and the percent of responses not peaking within 60 months.

The dotted line corresponds to this benchmark value transformed to a monthly basis as described in Section 2 . The impulse response of the accumulated forward premium should be compared to Fig. 2.

In line with Eichenbaum and Evans (1995) and Faust and Rogers (2003), the empirical results reveal that across all country pairs there is a forward discount premium but there is also considerable uncertainty regarding its size. When taking this uncertainty into account and calculating the Sharpe ratio $\mathrm{SR}_{\rho}$, one finds values between 1 and all the way up to 3. Analyzing the one-period forward premium and the associated Sharpe ratio yields similar conclusions. We conclude that the reward for risk of betting on violations of UIP is higher than the 'benchmark' reward for holding risk on the stock market by a factor somewhere between 2 and 5 . Note that the Sharpe ratio is calculated here conditional on a single monetary policy shock. To trade on this comparably high reward requires a portfolio that enables investors to solely focus on the forward discount risk associated with an observed monetary policy shock, hedging against all other disturbances. This implies the use of a portfolio with appropriate derivates and/or a trading strategy which is more sophisticated than a simple carry trade. Developing the appropriate hedging strategies in light of existing financial market instruments is beyond the scope of this paper.

\subsection{No delayed overshooting and forward discounting}

Alternatively, the delayed overshooting observation may be interpreted as a failure in appropriately identifying a monetary policy shock, rather than a result. The interesting question then is: is there nonetheless an economically significant violation of UIP on which smart investors may take bets if they observe a surprise relative tightening of monetary policy?
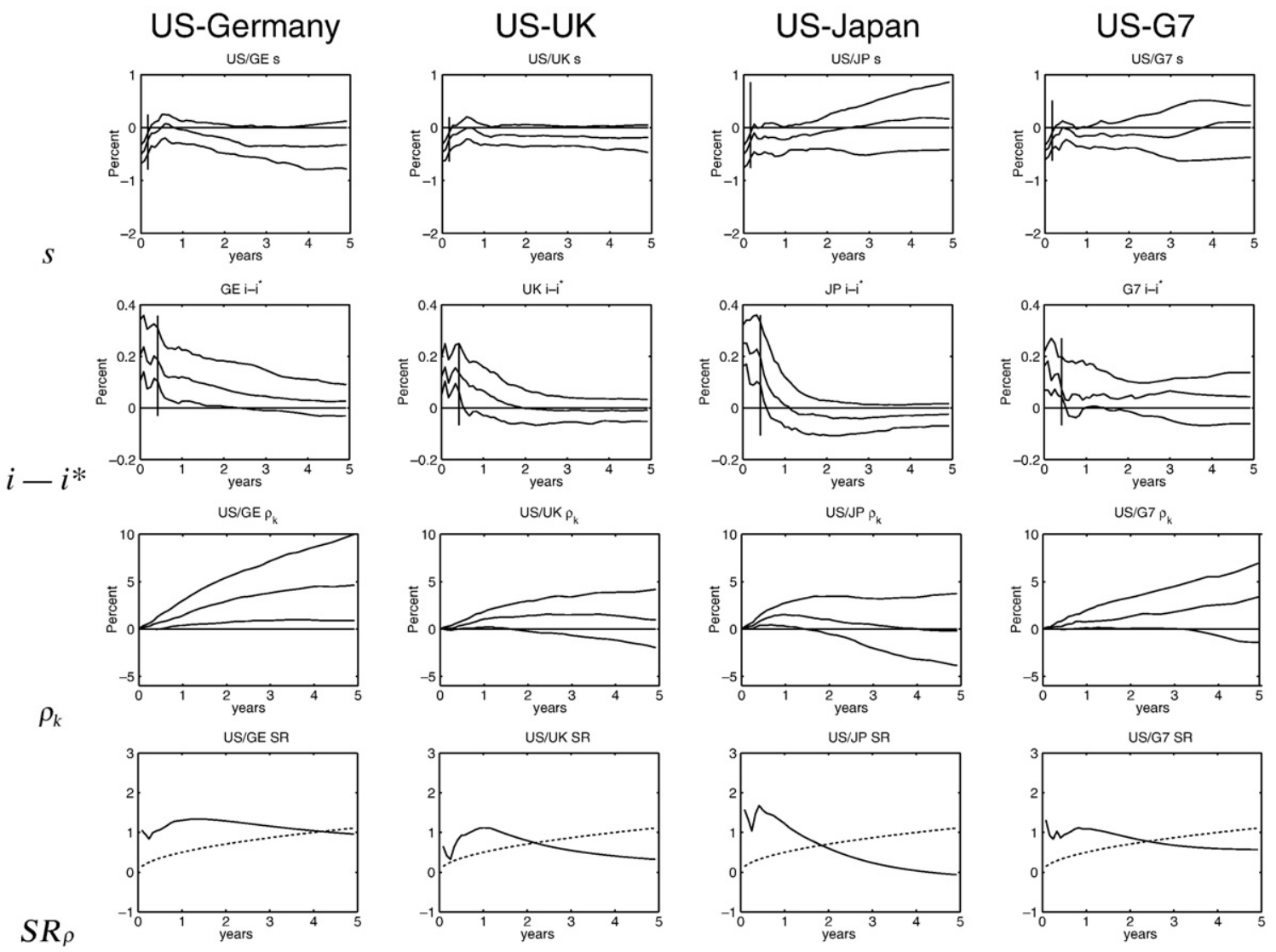

Fig. 6. Evidence on the forward discount puzzle. Notes: Results refer to identification II (see Table 1 ). The median impulse response and the $16 \%$ and $84 \%$ quantiles of the distribution are shown. 
To analyze this question, we employ our second identification strategy and additionally impose that domestic interest rates rise relative to foreign interest rates and that nominal exchange rates appreciate on impact and do not exhibit delayed overshooting, see Table 1. Fig. 6 plots the impulse responses of the nominal exchange rate $s$, the interest rate differential $i-i{ }^{*}$, the forward discount premium $\rho$ and the associated Sharpe Ratio $\mathrm{SR}_{\rho}$. The horizontal lines indicate that the impulse responses of the exchange rate as well of the interest rate differential are restricted by assumption. Note that we use the same scaling as in Fig. 4 to make comparisons easier. By construction, the exchange rates appreciate on impact and then depreciate to a long-run appreciated value, in line with the Dornbusch model.

First, consider the US-Germany case. Though the increase in the interest rate differential is approximately of the same size as before, the response of the US-German nominal exchange rate is much weaker. There occurs a sizeable and persistent forward premium. The posterior evidence for UIP violation is fairly strong, with the zero line just below the $16 \%$ quantile. Similar patterns can be observed considering the US-UK, the US-Japan and the US-G7 cases. There, the increases in the interest rate differentials are slightly lower than under identification $I$ and, therefore, the forward premia are smaller and less persistent. Furthermore, there is more posterior uncertainty regarding the sign of the forward premium, with the zero line below the $16 \%$ quantile just for the first 2 years. In all cases though, the magnitude of the forward premium is sizeable, even taking into account this uncertainty: the associated Sharpe ratios lie between 1 and 1.5. Thus, the reward for risk of betting on violations of the uncovered interest parity in response to a monetary policy shock at horizons up to 1 year is several times as large as the typical Sharpe ratio on equity markets.

All in all, our results indicate that across all country pairs there are likely to be sizeable positive forward premia even when there is no delayed overshooting. Moreover, the market price for risk of betting on violations of UIP is high, compared to equity investments. By contrast, Cushman and Zha (1997) and Kim and Roubini (2000) emphasize that they do not find statistically significant large deviations from UIP.

\subsection{Monetary policy and exchange rate volatility}

In this section we examine the identified monetary policy shocks associated with identification $I$. To do so we construct a stance of US monetary policy as a 12-month moving average window of the monetary policy shocks. The first panel of Fig. 7 plots the median of the US monetary policy stance considering the three country pairs US-UK, US-Germany and US-Japan. It is evident that the identified US monetary policy shocks follow the same pattern across country-pairs which make us feel confident concerning our identification strategy. The second graph focuses on the US-G7 and plots the 16, 50 and 84\% quantiles of the US monetary policy stance. Major episodes of US monetary tightening and loosening are reflected. For example, the monetary policy stance displays a clear spike during the recession of the early eighties, commonly identified with a surprise monetary tightening. One may alternatively wish to view the episode 1979-1982 as one where monetary policy switched to targeting monetary growth rates, with the interest rate fluctuations arising from demand rather than supply for money. This perspective suggests that one ought to allow for regime switches in the (now constant) time series for the impulse vector representing monetary policy surprises, and therefore for an extension of our methodology following e.g. the lead of Sims and Zha (2006). Note also that we observe a period of high volatility around 1985 in correspondence with the Plaza Agreement and the subsequent strong depreciation of the US Dollar. These episodes of considerable monetary disturbances are in line with those reported in Canova and De Nicolo (2002). The effects of the 1990-1991 and 2001 recessions are clearly shown by our monetary policy stance. Overall, the largest spikes take place during the recession in the early 1980s and in 1990-1991 while during the
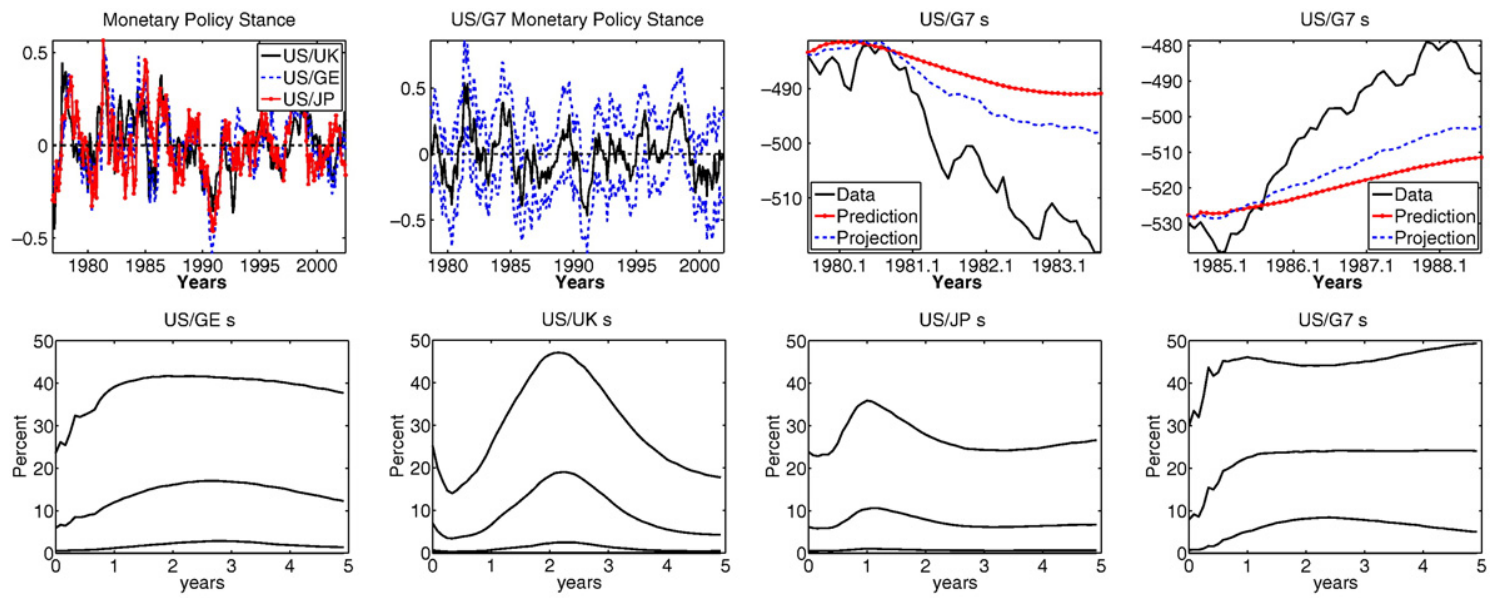

Fig. 7. Monetary policy shocks and exchange rate volatility. Notes: Results refer to identification I (see Table 1 ). The panels in the first row refer to median values. For the US-G7 monetary policy stance the $16 \%$ and $84 \%$ quantiles of the distribution are additionally shown. The second row reports the forecast error variance decompositions referring to a US monetary policy shock. The median and the $16 \%$ and $84 \%$ quantiles of the distribution are shown. 
1990s shocks are not as large. This is line with Rubio-Ramírez et al. (2005) who find only mild fluctuations in the interest rate during that time period.

To analyze how much US monetary policy shocks account for exchange rate fluctuations, we start with a comparison of the data with the prediction and the projection. The projection is the prediction if one had also known the monetary policy shocks but not all the other shocks and, thus, can be interpreted as the prediction available to the Fed planning a particular sequence of shocks. We consider two special periods: first, the Volcker Recession of the early 1980s as an example of extreme monetary policy, and, second, the mid 1980s as an example of a strong depreciation of the US exchange rate. The last two panels of the first line in Fig. 7 compare the data with the median of the prediction and projection. For clarity, we omit the error bands. The figures show that monetary policy shocks improve the prediction and, hence, partly account for the movements in the exchange rates.

To analyze this impact quantitatively, the second line of Fig. 7 presents the forecast error variance decomposition for the exchange rate movements explained by a US monetary policy shock considering the four country pairs. US monetary policy shocks account for roughly $10 \%$ of the US-German, the US-UK and the US-Japanese and about $20 \%$ of the US-G7 nominal exchange rate fluctuations at the median estimate. All in all, our results are in some contrast to Eichenbaum and Evans (1995) who estimated a percentage of 42, 26 and 23 for Germany, UK and Japan, respectively, at lags 31-36 using data until 1990. Their values are approximately on the line representing the $84 \%$ quantile of the posterior for the variance decomposition in our figures. Other examples for studies which find that nominal shocks have a substantial contribution in explaining exchange rate fluctuations are Clarida and Gali (1994), Rogers (1999) and Farrant and Peersman (2006). Our result that monetary policy shocks have a lower impact on exchange rate fluctuations is compatible with the weaker result of Faust and Rogers (2003) who state that the percentage might be anything between 8 and 56. However, since we are imposing more identifying assumptions, we find a narrower range than they do. Our results are also compatible with Kim and Roubini (2000) who estimate a percentage of 5, 16 and 17 at long horizons.

\subsection{Robustness analysis}

In our robustness analysis we considered alternative sign restriction sets, that e. g. involved additional restrictions on US industrial production. This did not change our findings. Considering the second identification set, it turned out to be crucial to restrict the interest rate differential since otherwise these responses were not significantly positive in all cases. Moreover, it was important to require the response of the exchange rate to be smaller in absolute value compared to the impact value for a long period following the shock to avoid strong appreciations in the medium run. Similar results could have been achieved by increasing the horizon $J$, however, this identification scheme implies much stricter assumptions and we decided to stick to the presented one.

To compare our results with those reported in Faust and Rogers (2003), we analyzed a subsample ending in 1997:12. The impulse responses of the subsample appeared to be very similar to the ones of the entire sample. Moreover, we added a constant to the benchmark VAR specification and our findings changed only in minor ways. It turned out that in particular for the country pairs US-Germany and US-Japan the responses are more clear-cut in terms of significance. We argue that our results are sharper than those of Faust and Rogers (2003) due to imposing more restrictions compared to the rather loose on-impact restrictions employed by these authors.

When using conventional identification methods including more variables implies a rising number of assumptions which become increasingly difficult to justify. The advantage of identification via sign restrictions is that we do not need many more assumptions. Hence, in our robustness analysis, we extended the benchmark VAR specification by adding possibly important variables. This extended VAR specification treats the US and the foreign country in a symmetric manner and takes into account some foreign monetary measure, the foreign price level and long term interest rates. Finally, we varied the lag length. With respect to these sensitivity checks the results appeared to be robust and the main conclusions were not altered.

\section{Conclusions}

This paper has estimated the effects of monetary policy shocks on exchange rates by applying an agnostic identification method recently proposed by Uhlig (2005a). A priori theorizing has been made explicit by imposing sign restrictions on the impulse responses of selected variables for a certain period following the shock.

We argue that our identifying sign restrictions are plausible because they generate monetary policy shocks that, firstly, match important episodes of US monetary tightening and loosening, and, secondly, most directly reflect what economists have in mind (or how economists informally evaluate empirical results) when thinking about monetary policy shocks. We view this identification strategy as a consequent pursuit of the agenda put forth by Sims (1980) of avoiding incredible identifying restrictions.

We restore the delayed overshooting and the forward discount puzzle originally stated by Eichenbaum and Evans (1995) that recently have been claimed to be fragile. Compared to Eichenbaum and Evans (1995), the median peak response appears to be somewhat earlier and at 26, 17 and 18 months after the shock for the three country pairs US-Germany, US-UK and US-Japan.

Regarding the forward discount puzzle, we evaluate the risk inherent in exploiting the forward discount premium by calculating the Sharpe ratio for a Bayesian investor, and find ratios of up to 3 even for investment horizons lower than 1 year, and thus considerably higher than those found on asset markets. Even if we rule out the delayed overshooting puzzle by construction, the Sharpe ratio is around one even at short horizons, and thus economically sizeable. 


\section{Appendix A}

\section{A.1. Data sources}

\begin{tabular}{|c|c|c|}
\hline Variable & Description & Source \\
\hline$y$ & Index of US industrial production & IMF Washington, line 66 \\
\hline$p$ & US consumer price index & IMF Washington, line 64 \\
\hline$n b r x$ & US nonborrowed reserves + extended credit/total reserves & Fed. Reserve Bank St. Louis \\
\hline$i$ & US 3-months treasury bill rate & IMF Washington, line 60c \\
\hline$y^{*}$ & Foreign industrial production & IMF Washington line 66 \\
\hline$p^{*}$ & Foreign consumer price index & IMF Washington, line 64 \\
\hline$i^{*}$ & Foreign short-term interest rate UK: 3-months treasury bill rate & IMF Washington, line 60c \\
\hline & Germany, Japan: short-term money market rate & IMF Washington, line 60b \\
\hline$S$ & Nominal exchange rate in dollar per foreign currency & Fed. Reserve Bank St. Louis \\
\hline$q$ & Real exchange rate per foreign currency & $=s-p+p^{*}$ \\
\hline$\rho$ & Forward discount premium (accumulated) & see Section 2 \\
\hline$\xi$ & Forward discount premium (for one period) & see Section 2 \\
\hline$S R_{\rho}$ & Sharpe ratio & see Section 2 \\
\hline
\end{tabular}

Variables are in logs except for interest rates. * refers to the foreign country. We consider Germany, UK and Japan. In addition we consider the aggregate of the G7 countries Canada, Germany, France, Italy, Japan and the UK.

\section{A.2. Aggregation method}

To construct an aggregate of the G7 countries Canada, Germany, France, Italy, Japan and the UK we first take growth rates to remove national basis effects. As country specific weight we consider the country's GDP relative to the total 6-country GDP calculated at purchasing power parity (PPP) values. The aggregated growth rates are then constructed as a weighted sum of the individual growth rates. To calculate levels the aggregate growth rates are cumulated starting from the initial base year.

\section{References}

Alvarez, F., Atkeson, A., Kehoe, P.J., 2002. Money, interest rates, and exchange rates with endogenously segmented asset markets. The Journal of Political Economy 110 (1), 73-112.

Alvarez, F., Atkeson, A., Kehoe, P.J., 2006. Time-varying risk, interest rates and exchange rates in general equilibrium. Federal Reserve Bank of Minneapolis, Working Paper 371 .

Bacchetta, P., van Wincoop, E., 2005. Rational inattention: a solution to the forward discount puzzle. National Bureau of Economic Research Working Paper 11633. Backus, D., Foresi, S., Telmer, C., 2001. Affine term structure models and the forward premium anomaly. The Journal of Finance 56 (1), $279-304$.

Bergin, P., 2006. How well can the new open economy macroeconomics explain the exchange rate and current account? Journal of International Money and Finance 25 (5), 675-701.

Bjørnland, H., 2006. Monetary policy and exchange rate overshooting: Dornbusch was right after all. Mimeo, University of Oslo.

Blanchard, O., 1989. A traditional interpretation of macroeconomic fluctuations. The American Economic Review 79 (5), $1146-1164$.

Canova, F., De Nicolo, G., 2002. Monetary disturbances matter for business fluctuations in the G-7. Journal of Monetary Economics 49 (6), 1131-1159.

Canova, F., Pina, J., 1999. Monetary policy misspecification in VAR models. CEPR Discussion Paper 2333.

Chari, V.V., Kehoe, P.J., McGrattan, E., 2002. Can sticky price models generate volatile and persistent real exchange rates? The Review of Economic Studies 69 (3), 533-563.

Christiano, L., Eichenbaum, M., 1992. Identification and the liquidity effect of a monetary policy shock. In: Cukierman, A., Hercowitz, Z., Leiderman, L. (Eds.), Political Economy, Growth and Business Cycles. MIT Press, Cambrige MA.

Clarida, R., Gali, J., 1994. Sources of real exchange rate fluctuations: how important are nominal shocks? Carnegie-Rochester Conference Series on Public Policy 41, $1-56$.

Cushman, D.O., Zha, T., 1997. Identifying monetary policy in a small open economy under flexible exchange rates. Journal of Monetary Economics 39 (3), $433-448$.

Dornbusch, R., 1976. Expectations and exchange rate dynamics. The Journal of Political Economy 84 (6), $1161-1176$

Dwyer, M., 1997. Dynamic response priors for discriminating structural vector autoregressions. Mimeo, UCLA.

Eichenbaum, M., Evans, C.L., 1995. Some empirical evidence of shocks to monetary policy on exchange rates. The Quarterly Journal of Economics 110 (4), $975-1010$.

Fama, E., 1984. Forward and spot exchange rates. Journal of Monetary Economics 14 (3), 319-338.

Farrant, K., Peersman, G., 2006. Is the exchange rate a shock absorber or a source of shocks? New empirical evidence. Journal of Money, Credit and Banking 38 (4), 939-961.

Faust, J., 1998. The robustness of identified VAR conclusions about money. Carnegie-Rochester Conference Series on Public Policy 49, $207-244$.

Faust, J., Rogers, J.H., 2003. Monetary policy's role in exchange rate behavior. Journal of Monetary Economics 50 (7), 1403-1622.

Froot, K.A., Thaler, R., 1990. Anomalies: foreign exchange. The Journal of Economic Perspectives 4 (1), 179-192.

Fry, R.A., Pagan, A.R., 2007. Some issues in using sign restrictions for identifying structural VARs. National Center for Economic Research Working Paper 14.

Gambetti, L., 1999. The real effects of monetary policy: a Neq VAR identification procedure. Rivista di Politica Economica 89 (12), $149-169$.

Gourinchas, P.-O., Tornell, A., 2002. Exchange rate dynamics, learning and misperception. National Bureau of Economic Research Working Paper 9391.

Gourinchas, P.-O., Tornell, A., 2004. Exchange rate puzzles and distorted beliefs. Journal of International Economics 64 (2), $303-333$.

Grilli, V., Roubini, N., 1995. Liquidity and exchange rates: puzzling evidence from the G-7 countries. Mimeo, Yale University.

Grilli, V., Roubini, N., 1996. Liquidity models in open economies: theory and empirical evidence. European Economic Review 40 (4), $847-859$.

Hansen, L.P., Hodrick, R.J., 1980. Forward exchange rates as optimal predictors of future spot rates: an econometric analysis. The Journal of Political Economy 88, 829-853.

Kalyvitis, S., Michaelides, A., 2001. New evidence on the effects of US monetary policy on exchange rates. Economics Letters 71 (2), $255-263$.

Kim, S., 2001. International transmission of U.S. monetary policy shocks: evidence from VARs. Journal of Monetary Economics 48 (2), $339-372$.

Kim, S., 2005. Monetary policy, foreign exchange policy, and delayed overshooting. Journal of Money, Credit and Banking 37 (4), $775-782$.

Kim, S., Roubini, N., 2000. Exchange rate anomalies in the industrial countries: a solution with a structural VAR approach. Journal of Monetary Economics 45 (3), $561-586$. 
Kollmann, R., 2001. Explaining international comovements of output and asset returns: the role of money and nominal rigidities. Journal of Economic Dynamics and Control 25 (10), 1547-1883.

Leamer, E.E., 1981. Is it a demand curve, or is it a supply curve? Partial identification through inequality constraints. The Review of Economics and Statistics 63 (3), 319-327.

Leeper, E.M., Sims, C.A., Zha, T., 1996. What does monetary policy do? Brookings Papers on Economic Activity 2 (2), 1-78.

Lewis, K.K., 1995. Puzzles in international financial markets. In: Grossman, G., Rogoff, K. (Eds.), Handbook of International Economics. Elsevier Science B.V.

Moore, M., Roche, M.J., 2002. Less of a puzzle: a new look at the forward Forex market. Journal of International Economics 58 (2), $387-411$.

Obstfeld, M., Rogoff, K., 1996. Foundations of International Macroeconomics. MIT Press, Cambrige MA.

Rogers, J.H., 1999. Monetary shocks and real exchange rates. Journal of International Economics 49 (2), 269-288.

Rubio-Ramírez, J.F., Waggoner, D.F., Zha, T., 2005. Markov-switching structural vector autoregressions: theory and application. Federal Reserve Bank of Atlanta, Working Paper 2005-27.

Sims, C.A., 1972. Money, income and causality. The American Economic Review 62 (4), 540-552.

Sims, C.A., 1980. Macroeconomics and reality. Econometrica 48 (1), 1-48.

Sims, C.A., Uhlig, H., 1991. Understanding unit rooters: a helicopter tour. Econometrica 59 (6), 1591-1599.

Sims, C.A., Zha, T., 2006. Were there regime switches in U.S. monetary policy? American Economic Review 96 (1), 54-81.

Strongin, S., 1995. The identification of monetary policy disturbances, explaining the liquidity puzzle. Journal of Monetary Economics 35 (3), $463-497$.

Verdelhan, A., 2006. A habit-based explanation of the exchange rate risk premium. Mimeo, Boston University.

Uhlig, H., 1994. What macroeconomists should know about unit roots: a Bayesian perspective. Econometric Theory 10 (4), 645-671.

Uhlig, H., 1998. The robustness of identified VAR conclusions about money: a comment. Carnegie-Rochester Conference Series on Public Policy 49, $245-263$.

Uhlig, H., 2005a. What are the effects of monetary policy on output? Results from an agnostic identification procedure. Journal of Monetary Economics 52 (2), $381-419$.

Uhlig, H., 2005b. Identification. Mimeo, University of Chicago. 